\title{
RESURGENCE OF EXTRA PULMONARY TUBERCULOSIS
}

\author{
Bag S', Deep N², Padhy S ${ }^{3}$ \\ ${ }^{1}$ Medical Education \& Training, Odisha, Bhubaneswar, India \\ ${ }^{2}$ AlIMS, Bhubaneswar, India \\ ${ }^{3}$ MKCG Medical College, Berhampur, India
}

\begin{abstract}
Introduction: Pulmonary tuberculosis is a public health challenge in the developing Nations. Extra pulmonary tuberculosis (EPTB) is still more challenging. EPTB with co-infection with human deficiencies virus (HIV) and malnutrition further aggravate the problems, the worst human health scenario in $3^{\text {rd }}$ world's nation. The objective of the study was to explore the magnitude of Extra tuberculosis and to assess the challenge faced in encountering the patient with malnutrition, HIV infection etc.
\end{abstract}

Method: All cases of tuberculosis registered under RNTCP in between 2009 - 2012 in MKCG Medical College, Berhampur, Odisha, India were scrutinized, 2596 case of EPTB were fished out. Details clinical, socio-economic, demographic, HIV status \& treatment outcome of these patients were subjected to critical analysis.

Results: Even though high prevalence of EPTB is encounter in poor socio-economic, rural back ground and people living with HIV and AIDS, upper and middle classes are not exempted complexities of diagnostic and therapeutic challenges are more often then not observed. Outcome is grim in immune weakened cases.

Conclusion: This study emphasized the resurgence of extra pulmonary tuberculosis involving all classes of people in Indian sub-continent. Challenges faced are delineated and determinant of clinical outcome in developing Nations have been highlighted.

Key words: DOTS, RNTCP, BPL \& APL, Socio-economic Status and Malnutrition,

\section{INTRODUCTION}

Tuberculosis remains a biggest public health challenge in India. Nearly two millions new tuberculosis (TB) cases are reported every year, two deaths occur every three minutes making it one of the deadliest in the country. ${ }^{1}$ Pulmonary tuberculosis (PTB) essentially experience in rural and poverty background, increasingly extra pulmonary tuberculosis (EPTB) is being diagnosed across the nation, its incidence is $10-15-\%$ in general and more than $50 \%$ in HIV co- infection

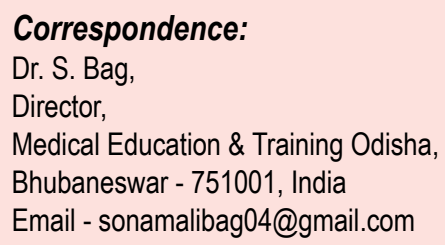

population. ${ }^{2}$ The rate of increase of new EPTB over rides that of the new TB cases. Forms of EPTB envisioned in order of commonness are lymphnode tuberculosis (LNTB), pleural, bones and joint, Urogental, meningeal, peritoneal and others. ${ }^{3}$ The critical issue here in this context is the identifying the magnitude of the problems of EPTB, perceived challenges and then building jointly an adequate answer to them. The objectives of the study were to describe the characteristic of EPTB in Indian subcontinent and to assess on factors that may contribute to disproportionately high prevalence in this population and to explore the association between age, sex socio-economic status and demographic parameter and risk of EPTB in Indian subcontinent. The aims of the study were to provide over view of EPTB in Indian subcontinent, pitfall and challenges while dealing with EPTB and impact assessment of HIV on EPTB and vice-versa and RNTCP on EPTB. 
Although many identifiable factors like poverty \& malnutrition, overcrowding frequent, migration of labour, diabetes mellitus, alcohol, smoking have been in discriminated to PTB ${ }^{4,5}$, host specific vulnerability are lacking in EPTB. Non specific symptoms and low yield of mycobacteria from presume site of involvement pose greater challenges, even though the basis principle of seeking mycobacterium tuberculosis isolation at every opportunity applies to EPTB as well. Histopathological, smear microscopy and culture, validated cartridge - base nucleic amplification test, adenosine deaminase are acceptable option. ${ }^{6}$

In the era before HIV pandemic, EPTB constitute $10-15 \%$ of all cases of TB in general practice. Resurgence of EPTB in post HIV pandemic delineates twin significant observation. HIV infected persons have markedly increased risk for primary or reactivation $\mathrm{TB}$ and second episodes of $\mathrm{TB}$ from exogenously re-infection. Thus EPTB accounts for very high prevalence in HIV +ve individuals. ${ }^{2,9}$

The treatment of EPTB follows standard Revised National Tuberculosis control programme (RNTCP). Guidelines depending on categorization and is consistent with international recommendation by WHO and International Union against Tuberculosis and Lung Disease (IUATLD). RNTCP is based on directly observe therapy short course (DOTS) and are instituted thrice weekly for six months. ${ }^{10 .}$ In tuberculosis meningitis (TBM) injection streptomycin instead of ethambutol and continuation phase up to six or seven months extending the total duration of treatment to eight to nine months. Steroid used and tapered over a period of six to eight weeks. It's worth mentioned here that EPTB seriously ill/not seriously ill depends on site of disease and condition of the patients.

\begin{tabular}{|l|l|}
\hline \multicolumn{2}{|l|}{ Table 1. Sources RNTC classification of EPTB } \\
\hline \multicolumn{1}{|c|}{ Seriously ill } & \multicolumn{1}{c|}{ Not seriously ill } \\
\hline TB meningitis disease & Lymph node TB ( LNTB) \\
\hline TB pericarditis & Unilateral plural effuses \\
\hline $\begin{array}{l}\text { Bilateral and extensive } \\
\text { plural effuse on }\end{array}$ & Bone excluding spine \\
\hline $\begin{array}{l}\text { Spinal TB with } \\
\text { neurological complication } \\
\text { (potts paraplegia) }\end{array}$ & Peripheral Jt \\
\hline Genito-urinary TB & \\
\hline
\end{tabular}

Recently there has been change in categorization, new Cat- I \& Retreatment (Cat-II) with abolition of Cat-III but it is yet to be geared up. ${ }^{10}$ With growing evidence it is globally recommended, that HIV infected TB patients should be treated with daily regimen. ${ }^{11}$

\section{METHODOLOGY}

Cases of tuberculosis have been reported in MKCG Medical College India over a period of five years from 2009-2013 were analyzed. Relevant diagnosis protocol adopted, treatment records and its outcome were diligently viewed and recorded.

Socio-economic status (Below Poverty Line (BPL) and Above Poverty Line (APL) and demographic profile Age, Sex, urban/rural background, poverty and malnutrition, migration of labour, overcrowded slums/homeless, alcoholism /smoker drug abuse and other relevant finding were documented. Proportion of EPTB, patients tested for HIV +ve were scaled out.

\section{Observation}

Of the 14032, cases of new tuberculosis reported, $2596(18.51 \%)$ had extra pulmonary involvement of tuberculosis including 2492 with exclusive extra pulmonary disease and 104 with pulmonary and extra pulmonary tuberculosis. HIV tested were positive for 541 (20.83\%).

\begin{tabular}{|c|c|c|c|}
\hline Site & Total & $\%$ & $\begin{array}{c}\text { HIV +ve } \\
\text { (Sero positive) }\end{array}$ \\
\hline Lymphonode & 1525 & 58.74 & 315 \\
\hline Pleural & 515 & 19.83 & 48 \\
\hline Abdominal & 218 & 8.38 & 48 \\
\hline Disseminated TB & 106 & 4.06 & 36 \\
\hline Spine TB & 84 & 3.23 & 58 \\
\hline TBM & 94 & 3.62 & 32 \\
\hline Skin/eye & 18 & 0.69 & 2 \\
\hline Renal/GUT & 32 & 1.23 & $\mathrm{NIL}$ \\
\hline Tuberculoma & 4 & 0.15 & 2 \\
\hline Total & 2596 & & $541(20.83)$ \\
\hline
\end{tabular}

\section{Socio-economic and demographic profile}

The mean age of EPTB was 32years (SD 18.5year) with male preponderance (male 1516 
(58.39\%), female-1080 (14.6\%). seventy eight percent belongs to BPL category, remaining are from affluent background (APL). Eighty percent $(80 \%)$ were with rural back ground mostly labour classes and slum dwellers. Alcohol consumption and smoking habit are invariably observed.

Vague generalized aesthenia with low grade irregular fever were the common clinical presentation seen $93.5 \%$ of cases followed by nodular swelling, abdominal and nonspecific chest pain. The site of involvement is represented in table 2.

\section{Diagnostic Profile of patients}

Table 3. Laboratory investigation-multiple investigation done in some cases, overlapping avoided

\begin{tabular}{|c|c|c|c|}
\hline $\begin{array}{l}\text { S. } \\
\text { No. }\end{array}$ & $\begin{array}{l}\text { Diagnostic } \\
\text { Profile }\end{array}$ & \multicolumn{2}{|c|}{$\begin{array}{l}\text { No of patients } \\
\text { HIV +ve }=541\end{array}$} \\
\hline A & $\begin{array}{l}\text { Clinical } \\
\text { profile }\end{array}$ & All & Outcome \\
\hline B & $\begin{array}{l}\text { FNAC/Biopsy } \\
\text { smear and } \\
\text { histopath } \\
\text { study (HP) }\end{array}$ & 1498 & $\begin{array}{l}\text { HP confirmed in } \\
1250 \text { HIV -ve } \\
58 \text { HIV+ve cases. }\end{array}$ \\
\hline C & $\begin{array}{l}\text { Isolation of } \\
\text { AFB/culture } \\
\text { Sputum AFB } \\
\text { smear +ve }\end{array}$ & $\begin{array}{l}408 \text { pleural } \\
\text { fluid and } \\
42 \text { dissemi- } \\
\text { nated }\end{array}$ & $\begin{array}{l}\text { - 18pleural fluid } \\
\text { (14HIV negative, } \\
4 \text { HIV+ve) and } \\
22 \text { HIV -ve } \\
\text { sputum + } 12 \\
\text { HIV + ve sputum } \\
=52 \text { smear for } \\
\text { AFB+ve) }\end{array}$ \\
\hline D & $\begin{array}{l}\text { Bio-chemical } \\
\text { cytological }\end{array}$ & $\begin{array}{l}\text { Pleural fluid- } \\
408 \text { cases } \\
\text { Cerebrospinal } \\
\text { fluid } 44 \text { cases } \\
\text { Ascitic fluid } 98 \\
\text { cases }\end{array}$ & $\begin{array}{l}\text { - All cases } \\
\text { pleocytosis with } \\
\text { lymphocytic pre } \\
\text { dominance } \\
\text { - Protein is } \\
\text { raised } \\
\text { - Glucose level } \\
\text { normal. }\end{array}$ \\
\hline$E$ & $\begin{array}{l}\text { Radiological } \\
\text { X-ray chest } \\
\text { Ultrasound } \\
\text { CT scan }\end{array}$ & $\begin{array}{l}\text { TB } \\
\text { abdomen } 98 \\
\text { TB Spine78 } \\
\text { Disseminated } \\
\text { TB 42 } \\
\text { TBM } 44 \\
\text { Other } 10\end{array}$ & $\begin{array}{l}\text { Disease specific } \\
\text { imaging features } \\
\text { detected. }\end{array}$ \\
\hline & & 2596 & $1360(52.38 \%)$ \\
\hline
\end{tabular}

Among the 2596 EPTB including 541 HIV positive cases, isolation of AFB possible in 18cases from pleural fluid \& 34 from sputum in disseminated tuberculosis respectively. LNTB had FNAC/biopsy done showed tubercular granulomatous changes in smear/ Histopathology suggesting confirmation of diagnosis in 1250 HIV negative and 58 HIV positive cases.

All case of plural effusion and spine TB had undergone X-ray of the affected parts.

All cases of the abdominal (98) TB Spine 78, TBM (44) \& others 10 had undergone disease specific imaging of the presumed site of involvement.

Over all $52.38 \%$ had confirmation of diagnosis through isolation of AFB bacteria from body fluid and with HP evaluation (1360 of 2596) cases. Remaining 1236 cases (47.61\%) diagnosis was based on clinical ground with indirect supportive evidence (biochemical, cytological and radiological, of which majority are HIV +ve cases, 467 of 541 $(86.32 \%)$.

\section{Outcome of RNTCP DOTS therapy}

Table 4. Not all patients had relevant records some patient lost followed up, hence the total present in the table do not tally with total number of patient. N-2596

\begin{tabular}{|l|c|c|c|c|}
\hline \multicolumn{1}{|c|}{ Site } & $\begin{array}{c}\text { Treat- } \\
\text { ment } \\
\text { com- } \\
\text { pleted } \\
\text { (HIV-ve) }\end{array}$ & Death & $\begin{array}{c}\text { Treatment } \\
\text { com- } \\
\text { pleted } \\
\text { (HIV+ve) }\end{array}$ & Death \\
\hline LNTB & 1498 & NIL & 248 & 48 \\
\hline $\begin{array}{l}\text { Plural effu- } \\
\text { sion }\end{array}$ & 408 & 6 & 38 & 10 \\
\hline Spine TB & 78 & 2 & 40 & 4 \\
\hline Abominated & 98 & NIL & 42 & 4 \\
\hline $\begin{array}{l}\text { Dissemi- } \\
\text { nated }\end{array}$ & 42 & 4 & 12 & 6 \\
\hline TBM & 44 & 8 & 30 & 10 \\
\hline Others & 10 & NIL & 1 & NIL \\
\hline Total & $\mathbf{2 1 7 8}$ & $\mathbf{2 0}$ & $\mathbf{4 1 1}$ & $\mathbf{8 2}$ \\
$\mathbf{( 8 3 . 8 )}$ & $\mathbf{( 0 . 9 1 )}$ & $\mathbf{( 7 8 . 8 )}$ & $\mathbf{( 1 9 . 9 1 \% )}$ \\
\hline
\end{tabular}

The 2178 out of $2596(83.8 \%)$ EPTB, HIV Negative TB including 411 out of $541(75.97 \%)$ HIV positive cases completed the prescribed treatment protocol. The death rate outnumbered (19.91) in the later group then the former $0.91 \%$ lost to follow up was a major problem. 


\section{DISCUSSION}

Pulmonary tuberculosis (PTB) is the most common form of tuberculosis ${ }^{12}$ of all types of TB in India accounting for $70-90 \%$ (12), EPTB constitute 10 $15 \%$ of TB. The situation is further grim in people living with HIV and AIDS (PLWHA) 52-67\%, ${ }^{13}$ when compared to the distribution of all newly diagnosed cases of tuberculosis in the population in the developing countries, a greater proportion of newly diagnosed EPTB occur in India ${ }^{9}$ while TB can develop at any $\mathrm{CD}_{4} \mathrm{~T}$ cell count, EPTB and disseminated form rise as immunodeficiency increase. ${ }^{15}$ There is decreased incidence of TB in HAART compared to ART-naive HIV infected persons. Since 1987, EPTB has been accepted as an AIDS defining disease. ${ }^{14}$ HIV infected persons have markedly increased for primary or reactivation TB and for second episodes of TB from exogenous re-infection. ${ }^{2,3}$ The current study also experience high incidence of EPTB (20.83) in patient with HIV co-infection. This increase in number has social and economic consequence in developing economy.

Socio-economic factors like poverty, malnutrition and tuberculosis are both problems of considerable magnitude in India. It is important to consider, how these problems tend to interact with each other. The link between tuberculosis and malnutrition has long been recognized; malnutrition may predisposed people to the development of clinical disease and tuberculosis can contribute to malnutrition. The direct evidence of effect of nutrition on tuberculosis is difficult because of whole complex of coincident environmental factors, never the less the weight of evidence still favours the view that malnutrition may be an important factor in the high mortality and morbidity from tuberculosis, three import questions are. Does malnutrition predispose to tuberculosis infection? Does malnutrition influence or modify the course of establish tuberculosis infection? Do nutritional factors influence their response to chemotherapy?

In the instance study, EPTB prevalence is very high in BPL and rural background (78\%) suggests low income leading to nutritional deficiencies, a contributing factor for such a high prevalence.

Substantial experimental evidence suggests that malnutrition can lead to secondary immune deficiency that increases the host susceptibility to infection. Increased risk of tuberculosis can result from alteration in the individual protective function of lymphocyties and macrophages because of nutritional insult. Thus Nutritional supplementation may represent a novel approach for test recovery in tuberculosis patients, raising nutritional status of population may prove to be an effective measure to control tuberculosis in developing nation. 15,16,17

Overcrowding, slum, migration of labour, homeless, drug abused, alcoholic and smoker are equally linked to HIV and TB. TB \& HIV act in deadly synergy. HIV infection increase the risk exposure to $T B$, progression of latent to active and death if HIV are not treated timely manner. ${ }^{5}$

Contrary to the previous belief "TB being a poor man disease", more and more EPTB are notified in affluent societies. It affects people across all socioeconomic strata, no group is exempt. Logically HIV is common amongst affluent societies and TB is common infection in People PLWHA. Thus TB can affect middle and upper class as well. If the immune system is not impaired, a person infected in tubercular bacillus has $10 \%$ risk during their life time of developing activities. The co-infection with HIV \& TB possesses numerous risks, $10 \%$ risk per year of contracting TB. ${ }^{18} \mathrm{HIV}$ epidemic has been main reason for resurgence of the EPTB. Expose to $T B$ is in evitable in the developing nation. But natural immunity keeps the germ at bay but often factors like the modern work culture, stressful work erratic life style weakened the immune and trigger disease, accounting for such high prevalence of EPTB in APL groups. ${ }^{16,17}$

Of the 2596 patients with EPTB, 2187 including 411HIV positive cases successfully completed. DOTS therapy as prescribed, lost to follow up was a major problems. Response to treatment, morbidity and mortality differ significantly between HIV negative and HIV positive group $(0.91 \%$ Vrs $19.91 \%)$. There has been increased rate of Drug Resistant TB, Multi Drug Resistant (MDR) and extremely drug Resistant (XDR) in HIV positive population which is difficult to treat and contribute to increase mortality. Treatment of HIV-TB co-infection is complex and associated with high drug toxicity and challenge related to adherence. Worldwide TB is most common opportunistic infection affecting HIV sero-positive individual and it is most common 
cause of death in patients with AIDS. ${ }^{18}$ The overall favourable response varied from 87 to $99 \%$ and all forms of EPTB except TB. Meningitis and other HIV associated EPTB where one third of the patients responded to treatment. $5,8 \& 14$

In present series response viewed 83.31 percent in all form of EPTB except TB meningitis and other HIV associated EPTB where one third of patients responded to treatment. These findings are similar to those reported. ${ }^{19}$

In summary extra pulmonary tuberculosis is more common in people living with HIV and AIDS, Malnutrition, Poverty with rural background are predisposing factors. Even though it is prevalent in people with Below Poverty Line (BPL) group, upper and middle class (APL) are not exempted from the disease. The extra-pulmonary tuberculosis underlines the important of developing acumen for early diagnosis and institution therapy within the existing systems. It is recommended that HIV is one of the common co-infection and the deadliest combination of the two devastating killer disease, needs a diligent fresh look. Its diagnostic challenge is difficult to treat; drug toxicity and Drug resistant warrant immediate exploration.

\section{REFERENCE}

1. Lopez AD, Mothers CD, Ezzali M, Jamison DT. Global and regional burden of disease and risk factor 2001; systematic analysis of population health data lancet 2006;367:1747-57.

2. Mohan A, Sharma SK. Epidemiology in Sharma SK, Mohan A, (Editor) Tuberculosis New Delhi, Jaypee Brother's Brother Medical Publisher 2001 P-14-29.

3. Sharma SK, Mohan A. Extra pulmonary tuberculosis, Indian J of Med Res 2004;120:31653.

4. Muriyandi $M$, Ramchandran $R$, Balasubrananian $R$, Narayan PR. Socio-economic dimension of Tuberculosis: Review of study over two decade from TRC. J. comn Dis 2006;38:204-15.

5. Dollin PJ, Raviglinone MC \& Kochi A. Global Tuberculosis and mortality during 1990-2000, Bull World Health Organization 1994;72:213-20.

6. World Health Organization Standards for TB care in India, standard testing for extra pulmonary tuberculosis 2014;30-32.
7. Deepjyoti V, Usha R sing, Kamlesh Sexena, Arate Bhatia, Bibha Talwar. Diagnosis of tubercular cervical lumphadenitis by FNAC, Microbiology \& Culture, Indian J Tuberculosis 1991;38:25.

8. Jain R, Sawhneys, Bhargava DK, Berry M. Diagnosis of Abdominal Tuberculosis : sonographic finding in patient with early disease. Am J : Roentgenol 1995;165:1391-5

9. Freser Ware, Balasubrananian R, A. Mohan, SK. Sharma. Extra-pulmonary Tuberculosis: management and control, Tuberculosis control in India 2010;95-114.

10. WHO guideline for treatment of tuberculosis 2010 update. www.tbcindia.org

11. World Health Organisation (WHO) in standard for TB care in India - addressing TB \& HIV condition and co-morbid condition 2014; 51.

12. S Tripathy, A Ananda, V. Inamadar. Clinical response of newly diagnosis HIV sero positive and sero negative pulmonary tuberculosis patient with RNTCP - short course regiment in Pune in India. Indian J Med Research 2011;521-528.

13. CorbettE.L., watt CJ, Walker N et al growing Burden of tuberculosis global trends and inter action with HIV epidemic Arch Intern Med 2003;163:1009.

14. Sharma Sk. Mohan A. Co-infection with human immune deficiency virus (HIV and Tuberculosis, Indian prospective. Indian J Tuberculosis 2004;5116.

15. HIV TB in India-By Soumya Swaminathan and V. Narendra. Deptt. of Clinical Research, TB Research Centre, India.

16. Rao KN, Gopalan C. The role of nutritional factors in tuberculosis, Indian J Tuberculosis 1966;13:1026.

17. Krishna Behari Gupta, Rajesh Gupta, Atulya Atreja, Manishverma, Suman V. Tuberculosis and nutrition. Lung India 2009;26:9-16.

18. Godfrey fausette $P$ and $H$. Ayles. Can we control tuberculosis in high HIV prevalence setting? Tuberculosis (Edins) 2003; 83:68-76.

19. K. Venugopal, PR srelatha, Sairu Philip \& Vijaya Kumar. Treatment outcome of Neuro Tuberculosis patients put on DOTS, Indian $J$ of tuberculosis 2008;55:1990-2002. 